\title{
Application of Differential Scanning Calorimetry to the Characterization of Biopolymers
}

\author{
Adriana Gregorova
}

Additional information is available at the end of the chapter

http://dx.doi.org/10.5772/53822

\section{Introduction}

Generally, polymers can be classified according to their thermal and mechanical properties into thermoplastics, thermosets and elastomers. Thermoplastics are amorphous or semicrystalline polymers that soft or melt during heating and solidify during cooling. The heating/cooling/heating process can be repeated without perceptible changes in thermal and mechanical properties of thermoplastics. Thermosets during heating undergo chemical changes and this process is irreversible. Elastomers can be vulcanized (cross-linked under assistance of heat, light, or special chemicals like sulfur, peroxides) that makes them reversibly stretchable for small deformations but vulcanization is the irreversible process.

The resulted properties of polymer materials and mixtures depend on the chemical and physical properties of neat polymers, additives as well as the used processing methodology. Differential scanning calorimetry (DSC) is a physical characterization method used to study thermal behavior of neat polymers, copolymers, polymer blends and composites. Generally, the non-isothermal DSC is used for the identification of neat basic polymers as well as the determination of their purity and stability. Amorphous polymers exhibit a glass transition temperature and semi-crystalline polymers may possess the glass transition temperature, a crystallization temperature, a melting temperature with various crystallization and melting enthalpies. However, these properties alter by both a presence of additives and applied polymer processing methodologies. Basically, a small quantity of sample (up to $10 \mathrm{mg}$ ) in pan from various materials (e.g. aluminum pan) and empty pan (reference) are treated under a defined temperature program (various combinations of thermal scansheating/cooling, and isothermal cycles), a pressure (stable) and an atmosphere (inert or reactive). Principally, sample and reference are maintained at the same temperature, while any transition occurred in the sample needs an energy supply, which is recorded by the DSC as a rate $\mathrm{dQ} / \mathrm{dt}$ against a temperature or a time. The DSC is the thermal analysis mainly used 
to determine a first-order transition (melting) and a second order endothermic transition (glass transition). The sudden change in the specific heat value, $C_{p}$ corresponds with the glass transition temperature as follows (Bower, 2002):

$$
\frac{d Q}{d t}=m C_{p}
$$

where $m$ is the mass of the sample.

However, the determination of the glass transition of polymers with a high crystallinity content is limited. The first-order transitions such as the crystallization of a polymer during a heating (cold crystallization) or a cooling cycle (crystallization) and a melting of polymer crystals can be described by the following formula (Bower, 2002):

$$
\frac{d Q}{d t}=\kappa \Delta T=\kappa \dot{T}\left(t-t_{0}\right)+\left.\frac{d Q}{d t}\right|_{t_{0}}
$$

where $\kappa$ is a thermal conductance between a sample holder and a sample, $\dot{T}$ is a temperature increase rate, and to is the start of transition.

Figure 1 shows the example of thermal transitions occurring in the injection molded sample of poly(lactic acid) (PLA) such as the glass transition, the cold crystallization and the melting. PLA is a thermoplastic aliphatic semi-crystalline biodegradable polyester. The presented molded sample had been cooled very rapidly during the processing (injection molding), so as the consequence during the second heating cycle appeared the cold crystallization peak.

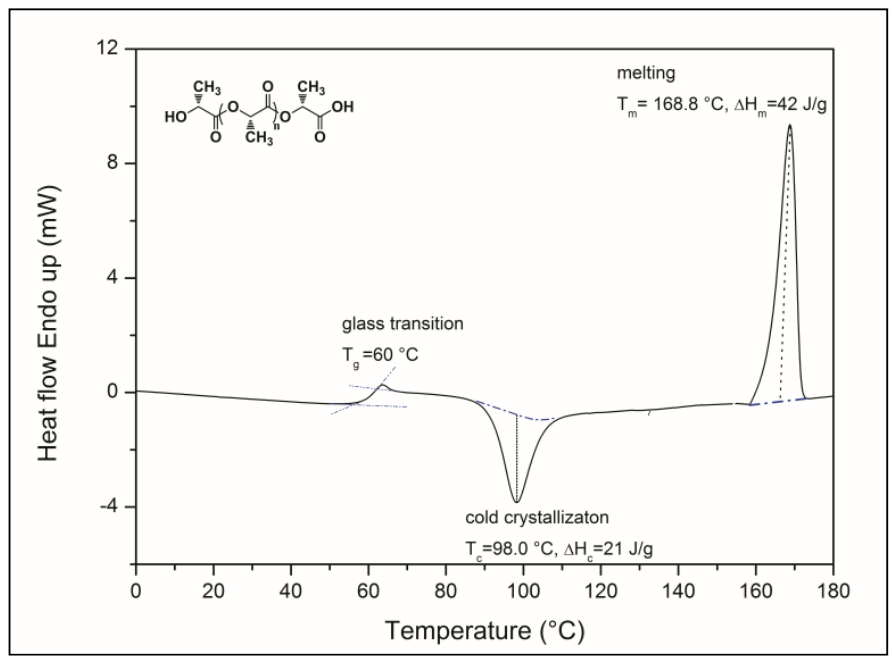

Figure 1. DSC thermogram of commercial poly(lactic acid) with $\overline{\mathrm{Mw}}=70400$ and PDI $=1.8$ detected during $2^{\text {nd }}$ heating cycle $\left(0-180^{\circ} \mathrm{C}, 10^{\circ} \mathrm{C} / \mathrm{min}, \mathrm{N}_{2}\right.$ atmosphere $)$ 
There are two types of DSC systems: 1) heat-flux (sample and reference pans are in an identical furnace block) and 2) power compensation (sample and reference pans are in two separate furnace blocks). From the practical point of view, it is important to pay attention to issues influencing an accuracy of results as follows:

- an instrument calibration, baseline subtractions,

- a selection of working gas $\left(\mathrm{N}_{2}, \mathrm{He}, \mathrm{O}_{2}\right)$,

- a selection of pans (e.g. Al-, Pt-, Ni-, Cu-, Quartz-pans, hermetic or non-hermetic pans),

- a proper thermal contact between sample and pans,

- a temperature program (heating cycle usually should start about $50^{\circ} \mathrm{C}$ under and finish about $10-20^{\circ} \mathrm{C}$ above the expected measured transition temperature),

- a sufficient slow scanning rate (to avoid the neglecting of the requested thermal transition),

- a sufficient purity and source of sample (neat polymer, polymer blend, composite, before or after processing, kind of the processing).

The aim of this chapter is to show some examples of the practical use of the DSC within the investigation of an amorphous biopolymer - lignin and semi-crystalline biodegradable polymer - poly(lactic acid) as well as to discuss the dependence of the thermal thermal properties on the value of the molecular weight of polymer, the polymer processing methodology and the presence of additives in the polymer mixtures.

\section{Effect of molecular weight on glass transition temperature}

Amorphous and semicrystalline polymers undergo a phase change from a glassy to rubbery stage at a glass transition temperature $(T g)$.

At $T g$ the segmental mobility of molecular chains increases and a polymer is more elastic and flexible. The value of $T g$ is dependent on the various factors such as a molecular weight of polymer, a presence of moisture, a presence of the crystalline phase (in the case of semicrystalline polymers). The dependence of $T g$ on a number-average molecular weight is described by Flory-Fox equation:

$$
T_{g}=T_{g}^{\infty}+\frac{K}{M_{n}}
$$

where $T_{g}^{\infty}$ is a glass transition for polymer with the infinite number-average molecular weight, $\mathrm{K}$ is an empirical parameter related to the free volume in polymer and $\mathrm{Mn}_{\mathrm{n}}$ is a number-average molecular weight of polymer.

\subsection{Thermal properties of Kraft lignin extracted with organic solvents}

In this sub-chapter, an example of the effect of various extraction solvents on molecular weight properties and thermal properties of Kraft lignin is shown. 
Lignin is polydisperse amorphous natural polymer consisting of branched network phenylpropane units with phenolic, hydroxyl, methoxyl and carbonyl groups. Its molecular weight properties as well as functional groups depend on its genetic origin and used isolation method. Differential scanning calorimetry is the useful method to determine its glass transition temperature. The value of $\mathrm{Tg}$ depends on the molecular weight, the thermal treatment, the humidity content and the presence of various contaminants in lignin sample.

Generally, phenyl groups together with the cross-linking restrict the molecular motion of lignin as an amorphous polymer in contrast to propane chains. Moreover, the intermolecular hydrogen bonding decrease $T g$ in the contrast to the methoxyl groups (Hatakeyama \& Hatakeyama, 2010). Lignin might be defined as a natural polymeric product produced by the enzymatic dehydrogenation polymerization of the primary methoxylated precursors such as $p$-coumaryl-, coniferyl- and sinapyl- alcohols (Figure 2).

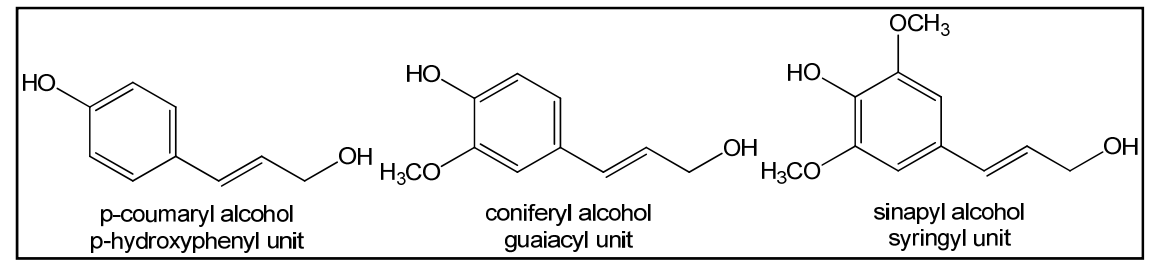

Figure 2. Lignin monomer building units

The structure of lignins depends on their natural origin and also on the external and internal conditions existing during lignin macromolecule synthesis and isolations. The large heterogeneity of lignin's structures makes it difficult to determine the overall structure of lignin. High variability of substituents on phenyl propane unit together with auto-coupling reaction gives rise to different lignin's structures depending on its origin and isolation method (Figure 3).

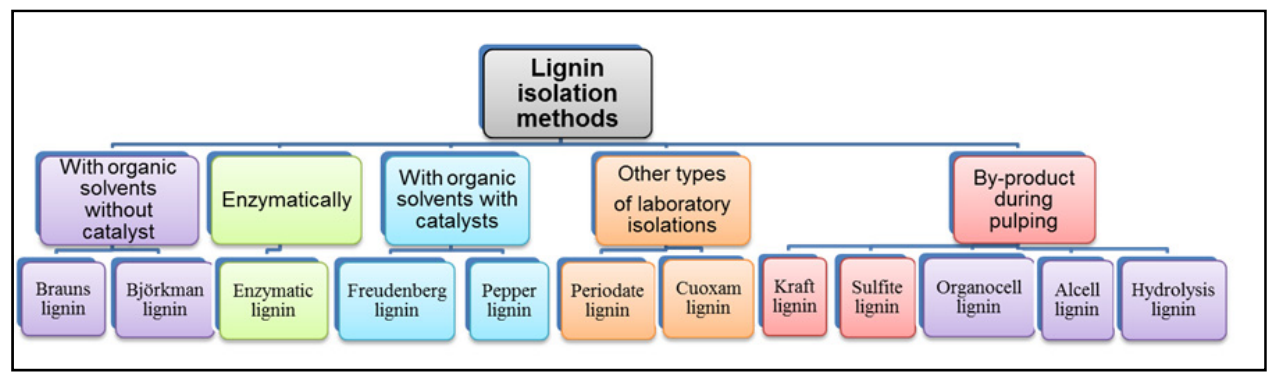

Figure 3. Lignin isolation methods

Kraft lignin used in this study was isolated from commercial spent pulping black liquor through the acidification with $98 \%$ sulphuric acid to $\mathrm{pH}=2$ (Zellstoff Pöls AG, Austria). Precipitated, filtered, washed and dried Kraft lignin was extracted at the room temperature with organic solvents with Hildebrand solubility parameters in the range of $18.5-29.7 \mathrm{MPa}^{1 / 2}$ (see Table 1) and then again filtered and dried. 


\begin{tabular}{|l|l|l|l|}
\hline Solvent & Chemical formula & $\begin{array}{l}\text { Hildebrand solubility parameter } \\
(\mathrm{MPa})^{1 / 2}\end{array}$ & Polarity index \\
\hline Dichlormethane & $\mathrm{CH}_{2} \mathrm{Cl}_{2}$ & 20.2 & 3.1 \\
\hline Tetrahydrofuran & $\mathrm{C}_{4} \mathrm{H}_{8} \mathrm{O}$ & 18.5 & 4.0 \\
Acetone & $\mathrm{CH}_{3} \mathrm{COCH} 3$ & 19.7 & 5.1 \\
\hline 1,4-Dioxane & $\mathrm{C}_{4} \mathrm{H}_{8} \mathrm{O}_{2}$ & 20.5 & 4.8 \\
\hline Methanol & $\mathrm{CH}_{3} \mathrm{OH}$ & 29.7 & 5.1 \\
\hline
\end{tabular}

Table 1. Solvents used for Kraft lignin extraction

The determined thermal and molecular weight properties of Kraft lignins are shown in Table 2. The glass transition temperature $(\mathrm{Tg})$ and the specific heat change $\left(\Delta \mathrm{C}_{\mathrm{p}}\right)$ were assessed by the differential scanning calorimetry (DSC) under the nitrogen flow, using the second heating cycle. Molecular weight properties were determined by a gel permeation chromatography (GPC) with the using of tetrahydrofuran as an eluent.

\begin{tabular}{|l|l|l|l|l|l|}
\hline Sample & $\begin{array}{l}\mathrm{T}_{\mathrm{g}} \\
\left({ }^{\circ} \mathrm{C}\right)\end{array}$ & $\begin{array}{l}\Delta \mathrm{C}_{\mathrm{p}} \\
\left(\mathrm{Jg}^{\circ} \mathrm{C}\right)\end{array}$ & $\begin{array}{l}\overline{\mathrm{M}_{n}} \\
(\mathrm{~g} / \mathrm{mol})\end{array}$ & $\begin{array}{l}\overline{\mathrm{M}_{w}} \\
(\mathrm{~g} / \mathrm{mol})\end{array}$ & PDI \\
\hline Kraft lignin_acetone & 114 & 0.086 & 1030 & 1800 & 1.7 \\
\hline Kraft lignin_tetrahydrofuran & 124 & 0.222 & 1170 & 3150 & 2.7 \\
\hline Kraft lignin_dichlormethane & 59 & 0.260 & 750 & 940 & 1.3 \\
\hline Kraft lignin_methanol & 105 & 0.368 & 910 & 1300 & 1.4 \\
\hline Kraf lignin_1,4-dioxane & 120 & 0.367 & 1150 & 3070 & 2.7 \\
\hline
\end{tabular}

Table 2. Thermal and molecular weight properties of Kraft lignins extracted in acetone, tetrahydrofuran, dichlormethane, methanol and 1,4-dioxane

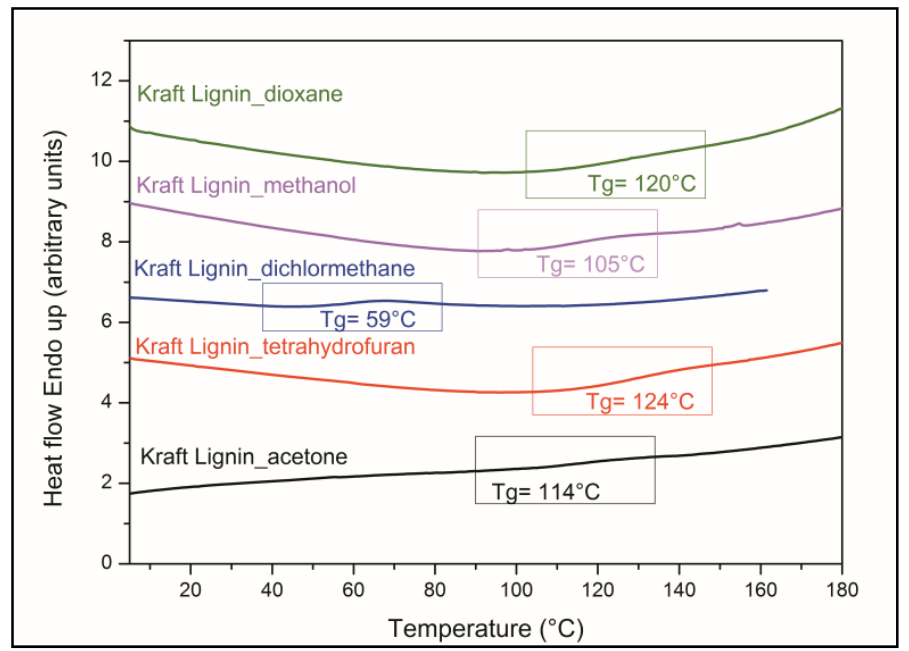

Figure 4. DSC thermograms of Kraft lignin extracted in acetone, tetrahydrofuran, dichlormethane, methanol and 1,4-dioxane detected during second heating scan $\left(5-180^{\circ} \mathrm{C}, 10^{\circ} \mathrm{C} / \mathrm{min}, \mathrm{N}_{2}\right.$ atmosphere) 
Figure 4 shows the thermograms of the individual Kraft lignins extracted with various organic solvents.

As can be seen from the results, the extraction as the last step used during the isolation process of Kraft lignin has a big effect on molecular as well as thermal properties of lignin.

\subsection{Thermal properties of Poly(lactic acid) synthetized through azeotropic dehydration condensation}

This sub-chapter shows the connection between PLA structure, its molecular weight properties and its thermal properties.

Poly(lactic acid) (PLA) is a biodegradable, thermoplastic, aliphatic polyester, which monomer can be derived from annually renewable resources. The glass transition temperature value is an important attribute that influences viscoelastic properties of PLA. The increase of the ambient temperature above $\mathrm{Tg}$ of PLA causes the sharp loss of its stiffness. The $T g$ values of PLA are influenced by its molecular weight, crystallinity, thermal history during processing, character of the side-chain groups and the presence of additives in the composition. The DSC analysis is one of the suitable methods to characterize the effect of the modification of PLA reactive side-chain groups on its thermal properties.

It is worth to mention that the melting temperature and the heat of fusion of polymers are influenced by thermal history applied during the polymer synthesis or processing. Therefore DSC results derived from $1^{\text {st }}$ heating cycle give information concerning an actual state of polymer crystals and the application of cooling cycle erase the previous thermal history, e.g. annealing during processing. Some semi-crystalline polymers with the slow crystallization ability like poly(lactic acid) do not have time to crystallize during cooling and thus crystallize during $2^{\text {nd }}$ heating cycle (cold crystallization) and consequently the melting peak may appear as double peak due to the content of different kinds of crystals. The melting behaviour of PLA is complex with regard to its multiple melting behaviour and polymorphism and has been intensively studied by several authors (Yasiniwa et al., 2004; Yasuniwa et al., 2006; Yasuniwa et al., 2007; Di Lorenzo, 2006).

PLA sample in the following example, marked as PLA 0, was synthetized by an azeotropic dehydration condensation in a refluxing boiling m-xylene from $80 \%$ L-lactic acid. During the azeotropic dehydration condensation samples PLA_1-3 were modified by succinic anhydride in the concentration 0.7, 1.3 and $2.5 \mathrm{~mol} \%$ (Gregorova et al., 2011a). Table 3 summarizes the nomenclature and molecular properties of non-modified PLA and PLA modified with various concentration of succinic anhydride.

Figure 5 shows DSC heating/cooling/heating thermogram of non-modified PLA with the molecular weight of $35600 \mathrm{~g} / \mathrm{mol}$.

Generally, glass transition temperature is determined from the second heating cycle to provide $T_{g}$ value independent on the thermal history during processing. The modification of PLA side-chain groups by succinic anhydride influenced not just molecular weight 
properties of PLA but also their thermal properties such as the glass transition temperature $(\mathrm{Tg})$, the melting temperature $(\mathrm{Tm})$ (in this case $\mathrm{Tm}$ was determined as the peak temperature of the melting peak) and the crystallinity (see Figure 6. and Table 4). As an adequate indicator of the crystallinity was chosen the specific heat of fusion, calculated as follows:

$$
\sum \Delta H=\left(\Delta H_{m 1}+\Delta H_{m 2}\right)-\Delta H_{c}
$$

where $\Delta \mathrm{H}_{\mathrm{m} 1}$ and $\Delta \mathrm{H}_{\mathrm{m} 2}$ are enthalpy values of the first and second melting peak, $\Delta \mathrm{H}_{\mathrm{c}}$ is the enthalpy of cold crystallization.

\begin{tabular}{|l|l|l|l|l|}
\hline Sample & $\begin{array}{l}\text { Concentration of } \\
\text { succinic anhydride } \\
(\mathrm{mol} \%)\end{array}$ & $\begin{array}{l}\overline{\mathrm{M}_{\mathrm{n}}} \\
(\mathrm{g} / \mathrm{mol})\end{array}$ & $\begin{array}{l}\overline{M_{\mathrm{w}}} \\
(\mathrm{g} / \mathrm{mol})\end{array}$ & PDI \\
\hline PLA_0 & 0 & 21400 & 35600 & 1.7 \\
\hline PLA_1 & 0.7 & 1950 & 3200 & 1.6 \\
\hline PLA_2 & 1.3 & 5600 & 9300 & 1.7 \\
\hline PLA_3 & 2.5 & 7000 & 13000 & 1.9 \\
\hline
\end{tabular}

Table 3. Description of PLA samples and their molecular properties determined by GPC in chloroform

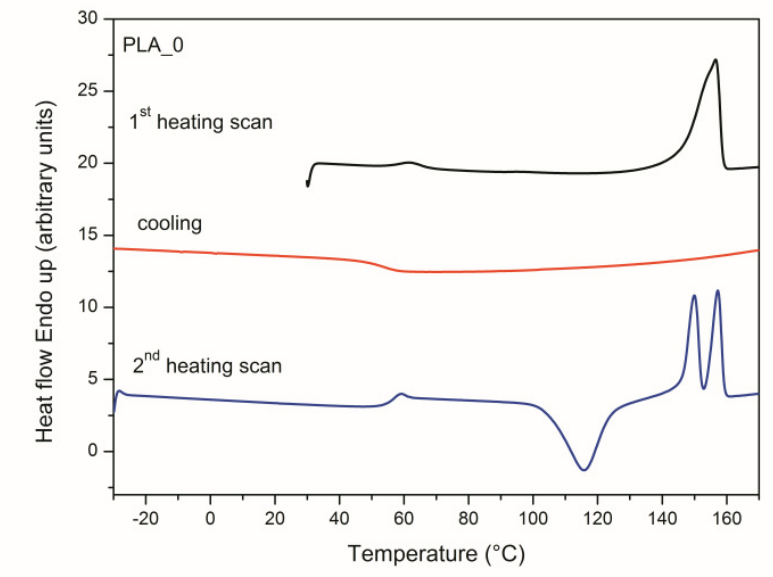

Figure 5. DSC thermogram of PLA_0 detected during heating/cooling/heating scan $\left(30-170^{\circ} \mathrm{C}, 170-0^{\circ} \mathrm{C}\right.$, $-30-170^{\circ} \mathrm{C}, 10^{\circ} \mathrm{C} / \mathrm{min}, \mathrm{N}_{2}$ atmosphere)

By the comparison of the content of the crystalline phase determined from $1^{\text {st }}$ heating and $2^{\text {nd }}$ heating cycle, it can be seen that PLA samples during second heating cycle exhibit an amorphous character despite of the initially crystalline character determined from $1^{\text {st }}$ heating scan. A thermal history is very important issue that influence the arrangement of amorphous/crystalline phase and consequently influence the physico-mechanical properties of poly(lactic acid). 


\begin{tabular}{|c|c|c|c|c|c|c|c|c|c|c|c|c|c|}
\hline \multirow[b]{2}{*}{ Sample } & \multicolumn{5}{|c|}{$1^{\text {st }}$ heating cycle } & \multicolumn{8}{|c|}{$2^{\text {nd }}$ heating cycle } \\
\hline & $\begin{array}{l}\mathrm{T}_{\mathrm{m} 1} \\
\left({ }^{\circ} \mathrm{C}\right)\end{array}$ & $\begin{array}{l}\Delta \mathrm{H}_{\mathrm{m} 1} \\
(\mathrm{~J} / \mathrm{g})\end{array}$ & $\begin{array}{l}\mathrm{T}_{\mathrm{m} 2} \\
\left({ }^{\circ} \mathrm{C}\right)\end{array}$ & $\begin{array}{l}\Delta \mathrm{H}_{\mathrm{m} 2} \\
(\mathrm{~J} / \mathrm{g})\end{array}$ & $\begin{array}{l}\Sigma \Delta \mathrm{H} \\
(\mathrm{J} / \mathrm{g})\end{array}$ & $\begin{array}{l}\mathrm{T}_{\mathrm{g}} \\
\left({ }^{\circ} \mathrm{C}\right)\end{array}$ & $\begin{array}{l}\mathrm{T}_{\mathrm{c}} \\
\left({ }^{\circ} \mathrm{C}\right)\end{array}$ & $\begin{array}{l}\Delta \mathrm{H}_{\mathrm{c}} \\
(\mathrm{J} / \mathrm{g})\end{array}$ & $\begin{array}{l}\mathrm{T}_{\mathrm{m} 1} \\
\left({ }^{\circ} \mathrm{C}\right)\end{array}$ & $\begin{array}{l}\Delta \mathrm{H}_{\mathrm{m} 1} \\
(\mathrm{~J} / \mathrm{g})\end{array}$ & $\begin{array}{l}\mathrm{T}_{\mathrm{m} 2} \\
\left({ }^{\circ} \mathrm{C}\right) \\
\end{array}$ & $\begin{array}{l}\Delta H_{\mathrm{m} 2} \\
(\mathrm{~J} / \mathrm{g})\end{array}$ & $\begin{array}{l}\Sigma \Delta \mathrm{H} \\
(\mathrm{J} / \mathrm{g})\end{array}$ \\
\hline PLA_0 & 157 & 37.8 & - & - & 37.8 & 56 & 116 & 27.3 & 150 & 14.3 & 157 & 15.4 & 2.4 \\
\hline PLA_1 & 145 & 18.8 & - & - & 18.8 & 47 & 106 & 27.1 & 132 & 9.5 & 143 & 18.6 & 1.0 \\
\hline PLA_2 & 143 & 10.7 & 152 & 15.8 & 26,5 & 50 & 107 & 23.6 & 140 & 7.8 & 151 & 20.0 & 4.2 \\
\hline PLA_3 & 139 & 7.4 & 152 & 13.5 & 20,9 & 50 & 109 & 25.9 & 139 & 9.9 & 150 & 20.1 & 4.1 \\
\hline
\end{tabular}

Table 4. Thermal properties of PLA synthetized through the azetropic dehydration condensation from $80 \%$ L-Lactic acid and modified by succinic anhydride

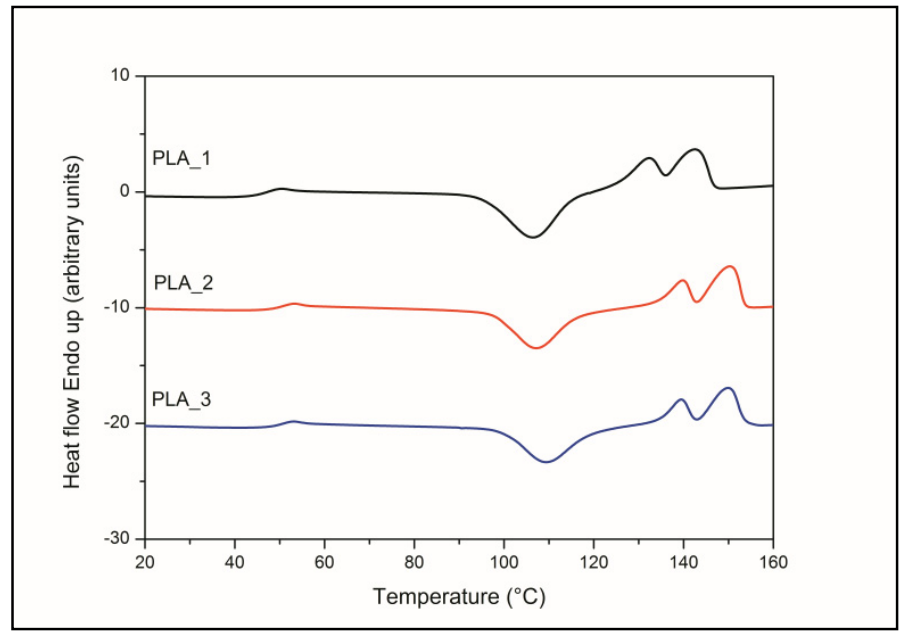

Figure 6. DSC thermograms of PLA samples with modified side chain groups and various molecular properties detected during second heating $\operatorname{scan}\left(-30-170^{\circ} \mathrm{C}, 10^{\circ} \mathrm{C} / \mathrm{min}, \mathrm{N}_{2}\right.$ atmosphere)

\section{Effect of thermal treatment on thermal behavior of poly(lactic acid)}

As was already discussed in the previous sub-chapter, PLA is the semi-crystalline polymer with the slow crystallization ability. Mechanical properties as well as gas barrier properties of PLA depend also on its gained crystallinity value. The resulting crystallinity of PLA can be modified by a thermal treatment (annealing) for some time at the crystallization temperature during the thermal processing of a sample. The change of a crystals size and a form during the annealing can be revealed by a X-Ray analysis but the change in the percentage of crystalline phase is detectable also by the DSC analysis. This section describes the progress of the PLA crystalline phase due to the applied annealing treatment. Moreover, the obtained DSC data are supported by a light microscopy study.

The followed data were obtained by the analysis of the thermal compression molded poly(lactic acid) synthetized by the azeotropic dehydration condenstation (PLA_3) (Figure 7). 
<smiles>C[C@@H](O)C(=O)O</smiles>

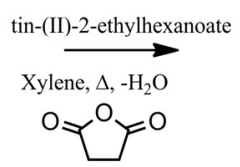<smiles>C[C@H](OC(=O)C(C)(C)OC(=O)[C@H](C)OC(=O)[C@H](C)OC(=O)CCC(=O)O)C(=O)O</smiles>

Figure 7. Structure of PLA_3 (PLA synthesized by the azeotropic dehydration condensation and modified by $2.5 \mathrm{~mol} \%$ succinic anhydride)

The crystallinity value of PLA was modified during thermoprocessing by the thermal annealing at $110^{\circ} \mathrm{C}$ for $0,5,10,15,20,30,45,60$ and $120 \mathrm{~min}$, respectively and afterwards cooled down to the room temperature. The samples are designated as PLA_3_110_X, where $\mathrm{X}$ indicates annealing time.

The clear effect of the thermal annealing on the PLA melting behavior is shown in Figure 8.

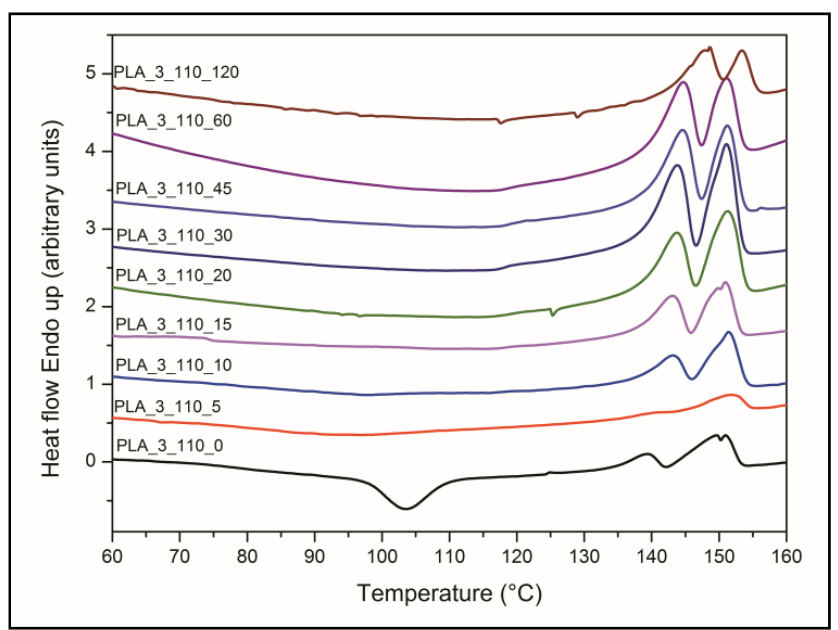

Figure 8. DSC thermograms of PLA_3 annealed at $110^{\circ} \mathrm{C}$ for $0-120 \mathrm{~min}\left(1^{\text {st }}\right.$ heating, $30-160^{\circ} \mathrm{C}, 10^{\circ} \mathrm{C} / \mathrm{min}$, $\mathrm{N}_{2}$ atmosphere)

The change of the annealing time influenced the value of the specific melting enthalpy $(\Sigma \Delta \mathrm{H})$ due to the enabling of a growth of crystals (Table 5).

The crystals morphology of PLA samples annealed at $110^{\circ} \mathrm{C}$ and various times were investigated by using of the light microscope with crossed polarizers (Figure 9). It can be seen that a shape and dimensions of the created crystals depend on the annealing time.

The DSC as well as the light microscopy analyses showed that the thermo-processed films without the annealing processing step have an amorphous character (Figure 9a), and on other side the application of the annealing processing step at $110^{\circ} \mathrm{C}$ during thermoforming instead of a quick direct cooling step (to the room temperature) promotes the growth of crystals. A kind, a size, a thickness, and a content of arisen crystals depend on the annealing temperature and time. DSC data displayed in Table 5 showed that the value of the specific 
12 Differential Scanning Calorimetry, Isothermal Titration Calorimetry and Microcalorimetry

\begin{tabular}{|l|l|l|l|l|l|l|l|l|l|}
\hline \multirow{2}{*}{ Sample } & \multicolumn{9}{|l|}{$1^{\text {st }}$ heating cycle } \\
\cline { 2 - 10 } & $\begin{array}{l}\mathrm{T}_{\mathrm{c} 1} \\
\left({ }^{\circ} \mathrm{C}\right)\end{array}$ & $\begin{array}{l}\Delta \mathrm{H}_{\mathrm{c} 1} \\
(\mathrm{~J} / \mathrm{g})\end{array}$ & $\begin{array}{l}\mathrm{T}_{\mathrm{m} 1} \\
\left({ }^{\circ} \mathrm{C}\right)\end{array}$ & $\begin{array}{l}\Delta \mathrm{H}_{\mathrm{m} 1} \\
(\mathrm{~J} / \mathrm{g})\end{array}$ & $\begin{array}{l}\mathrm{Tm} \text { Peak height } \\
(\mathrm{mW})\end{array}$ & $\begin{array}{l}\mathrm{T}_{\mathrm{m} 2} \\
\left({ }^{\circ} \mathrm{C}\right)\end{array}$ & $\begin{array}{l}\Delta \mathrm{H}_{\mathrm{m} 2} \\
(\mathrm{~J} / \mathrm{g})\end{array}$ & $\begin{array}{l}\mathrm{T}_{\mathrm{m} 2} \text { Peak height } \\
(\mathrm{mW})\end{array}$ & $\begin{array}{l}\Sigma \Delta \mathrm{H} \\
(\mathrm{J} / \mathrm{g})\end{array}$ \\
\hline PLA_3_110_0 & 104 & 21.8 & 139 & 4.6 & 0.14 & 151 & 20.5 & 0.39 & 3.3 \\
\hline PLA_3_110_5 & - & - & - & - & - & 152 & 12.6 & 1.18 & 12.6 \\
\hline PLA_3_110_10 & - & - & 143 & 6.1 & 0.26 & 151 & 15.4 & 0.67 & 33.5 \\
\hline PLA_3_110_15 & - & - & 143 & 20.1 & 0.51 & 151 & 13.5 & 0.65 & 35.8 \\
\hline PLA_3_110_20 & - & - & 143 & 19.9 & 0.76 & 151 & 15.9 & 1.0 & 36.4 \\
\hline PLA_3_110_30 & - & - & 144 & 20.8 & 1.1 & 151 & 15.6 & 1.4 & 27.5 \\
\hline PLA_3_110_45 & - & - & 144 & 14.5 & 0.87 & 151 & 13.0 & 1.03 & 27.0 \\
\hline PLA_3_110_60 & - & - & 144 & 15.2 & 0.87 & 151 & 11.8 & 0.88 & 15.9 \\
\hline PLA_3_110_120 & - & - & 149 & 10.3 & 0.44 & 154 & 5.6 & 0.44 & \\
\hline
\end{tabular}

Table 5. Thermal properties of PLA_3 films, annealed at $110^{\circ} \mathrm{C}$ for $0-120 \mathrm{~min}$

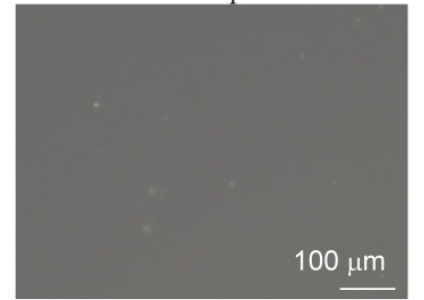

a) PLA 31100

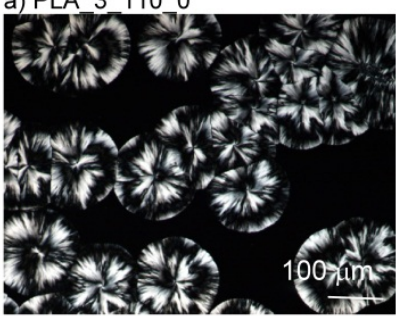

d) PLA $3 \_110 \_15$

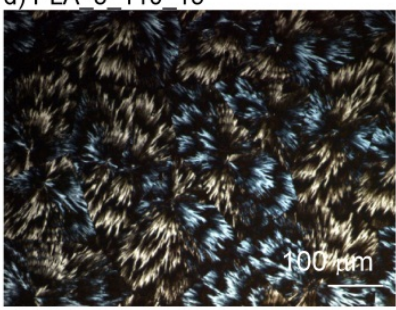

g) PLA_3_110_45

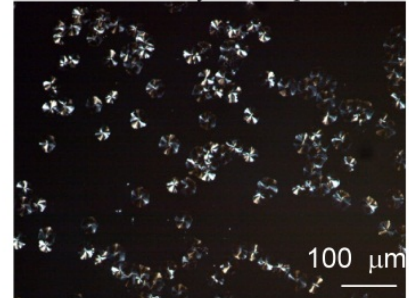

b) PLA 3 110_5

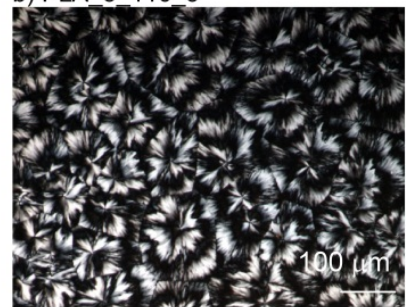

e) PLA $3 \quad 11020$

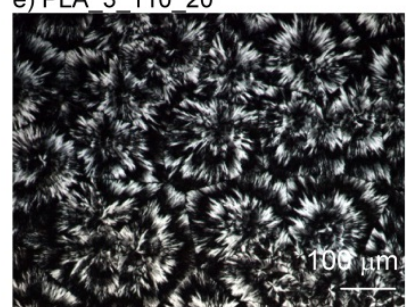

h) PLA_3_110_60

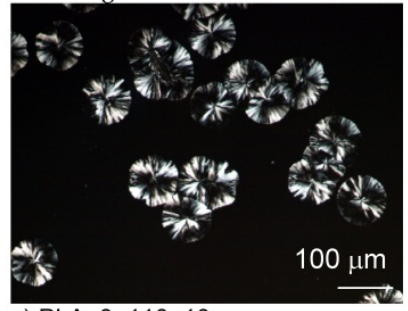

c) PLA $3 \quad 110 \quad 10$

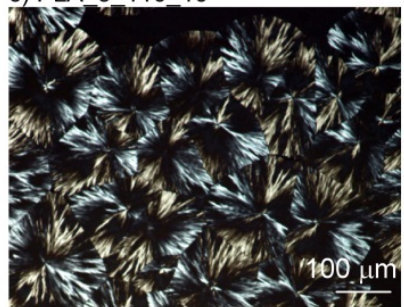

f) PLA $3 \quad 110 \quad 30$

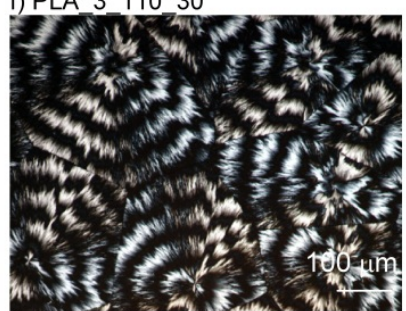

i) PLA $3110 \_120$

Figure 9. Polarized optical micrographs (magnification 400×) of crystals of polylactic acid modified with succinic anhydride (PLA_3) grown from the melt and annealed at $110^{\circ} \mathrm{C}$ for $5-120 \mathrm{~min}$

heat of fusion markedly increased up to $15 \mathrm{~min}$ of the annealing time, but the extension of the annealing time up to $30 \mathrm{~min}$ increased $\Sigma \Delta H$ just slightly and further extension of the 
annealing time even decreased it. However, light micrographs of PLA_3 (see Figure $9 \mathrm{~b}$-i) show clear differences of the character of crystals, arisen from the samples annealed under and above $30 \mathrm{~min}$. The application of the longer annealing time caused the creation of overgrowth crystals. The difference in the character of crystals can be also detected by the change of the height of the melting peak and by their shift to the higher temperatures. The value of $\Sigma \Delta H$ of PLA annealed for $120 \mathrm{~min}$ (PLA_3_110_120) is comparable to that of annealed just for $10 \mathrm{~min}$, however the crystal morphology is markedly different. Furthermore, the change of the crystal morphology was indicated by the increase of the melting temperature ( $\mathrm{T}_{\mathrm{m} 1}$ and $\mathrm{T}_{\mathrm{m} 2}$ ) about 10 and $3^{\circ} \mathrm{C}$, respectively. Also the optical micrograph displayed in Figure $9 \mathrm{i}$ showed the difference in the crystal morphology in a comparison to the previous samples annealed at the lower time. As a remark can be highlighted that the crystal morphology has an essential influence on resulting physicomechanical properties of PLA materials.

\section{Thermal stability of biopolymers determined by DSC}

\subsection{Effect of functional end groups on poly(lactic acid) stability}

The intramolecular transesterification with the formation of cyclic oligomers and byproducts like acrylic acid, carbon oxide and acetaldehyde is considered as one of the main mechanisms of the PLA thermal degradation. Above $200^{\circ} \mathrm{C}$ five reaction pathways have been found: intra-and intermolecular ester exchange, cis-elimination, radical and concerted nonradical reactions, radical reactions and Sn-catalyzed depolymerisation (Kopinke et al., 1996). It has been suggested that $\mathrm{CH}$ groups of the main chain and the character of functional end groups affect thermal and hydrolytic sensitivity of PLA (Lee et al., 2001; Ramkumar \& Bhattacharya, 1998). In our previous work it was shown that thermal sensitivity of PLA might be improved by the modification of its functional end groups (Gregorova et al., 2011a). This sub-chapter shows that the DSC analysis can be used to determine the thermal stability of poly(lactic acid).

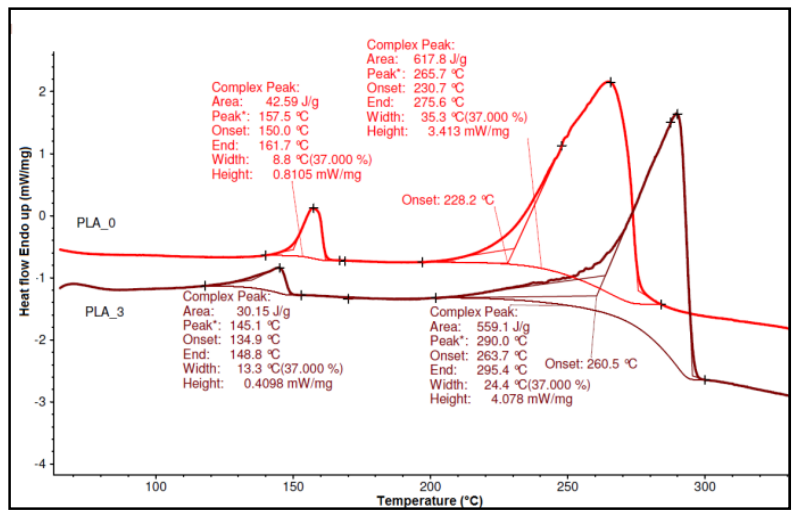

Figure 10. DSC curves of low molecular weight PLA synthetized by azeotropic dehydration condensation (PLA_0) and modified by 2.5 mol.\% succinic anhydride (PLA_3), detected by $1^{\text {st }}$ heating cycle from 30 to $350^{\circ} \mathrm{C}$ at heating rate of $10^{\circ} \mathrm{C} / \mathrm{min}$, in nitrogen flow. 
The obtained DSC data, displayed in Figure 10, showed that the modification of low molecular weight PLA with succinic anhydride caused the decrease of its melting temperature and crystallinity. Furthermore, the detected values of the onset degradation temperature, the degradation temperature in peak and the enthalpy of degradation indicate the improvement of thermal stability, caused by the modification of hydroxyl functional end group by succinic anhydride.

\subsection{Stabilizing effect of lignin used as filler for natural rubber}

Natural rubber (NR) is highly unsaturated polymer exhibiting poor resistance to oxidation. For the inhibition of the degradation process during thermo-oxidation can be used stabilizers such as phenol and amine derived additives. NR for the production of vulcanized products is mixed with the number of the other compounding ingredients to obtain the desired properties of vulcanizates (e.g sulfur, accelerators, and filler). Lignin is biopolymer that can be used as an active filler for rubber. It was found that some lignins can play dual role in rubber compounds, influencing their mechanical properties as well as their stability [11].

The obtained data were obtained by using of vulcanizates based on natural rubber (NR) and filled with 0, 10, 20 and $30 \mathrm{phr}$ of Björkman beech lignin $(\mathrm{Mw}=2000, \mathrm{PDI}=1.2)$ (Kosikova et al., 2007). Samples are designated as NR_Lignin_X, where X presents concentration of lignin in phr (parts per hundred rubber).

Table 6 shows values of degradation temperature determined as the onset and the peak temperature in dependence on the lignin concentration in natural rubber vulcanizates. It can be seen that lignin used as filler exhibit also the stabilizing effect, while the best stabilizing effect was reached in the case of 20 phr presence of Björkman beech lignin.

\begin{tabular}{|l|l|l|l|}
\hline Sample & $\begin{array}{l}\text { Tonset } \\
\left({ }^{\circ} \mathrm{C}\right)\end{array}$ & $\begin{array}{l}\mathrm{T}_{\text {peak }} \\
\left({ }^{\circ} \mathrm{C}\right)\end{array}$ & $\begin{array}{l}\Delta \mathrm{H} \\
(\mathrm{J} / \mathrm{g})\end{array}$ \\
\hline NR_Lignin_0 & 184 & 326 & 886 \\
\hline NR_Lignin_10 & 183 & 349 & 833 \\
\hline NR_Lignin_20 & 301 & 368 & 363 \\
\hline NR_Lignin_30 & 296 & 364 & 318 \\
\hline
\end{tabular}

Table 6. DSC data evaluated from $1^{\text {st }}$ heating cycle analysis $\left(30-500^{\circ} \mathrm{C}, 10^{\circ} \mathrm{C} / \mathrm{min}\right.$, air atmosphere) of vulcanizates based on natural rubber (NR) and NR filled with Björkman beech lignin (Kosikova et al., 2007)

\subsection{Stabilizing effect of lignin used as additive in polypropylene}

It was already reported that the lignin in the certain circumstances can support the biodegradability of polymer samples (Kosikova et al., 1993a; Kosikova et al., 1993b; Mikulasova\&Kosikova, 1999). On the other side lignin with the important functional groups and the low molecular weight with the narrow polydispersity can be used as the stabilizer 
for polypropylene (Gregorova et al., 2005a). This section shows that DSC is the sensitive method able to determine the stabilizing effect of lignin in polypropylene.

The polypropylene samples, stabilized with Björkman beech lignin (Mw=2000, PDI=1.2), used in this example were thermal processed with the injection molding (Gregorova et al., 2005a). Figure 11 shows the change of the onset oxidation temperature (Tonset) recorded for polypropylene stabilized with lignin. Generally, additives should be compatible with polymer matrix to keep physico-mechanical properties on the desired level; therefore it is necessary to know the lowest active concentration of the additive. It can be seen that the studied Björkman beech lignin increased Tonset about $15-30^{\circ} \mathrm{C}$ depending on the used concentration. On the base of the obtained mechanical properties of polypropylene/lignin composites, $2 \mathrm{wt} \%$ of Björkman beech lignin was determined as the optimal concentration to stabilize polypropylene. It was shown that the higher concentration of non-modified lignin deteriorated the mechanical properties of polypropylene (Gregorova et al., 2005a, Gregorova et al., 2005b).

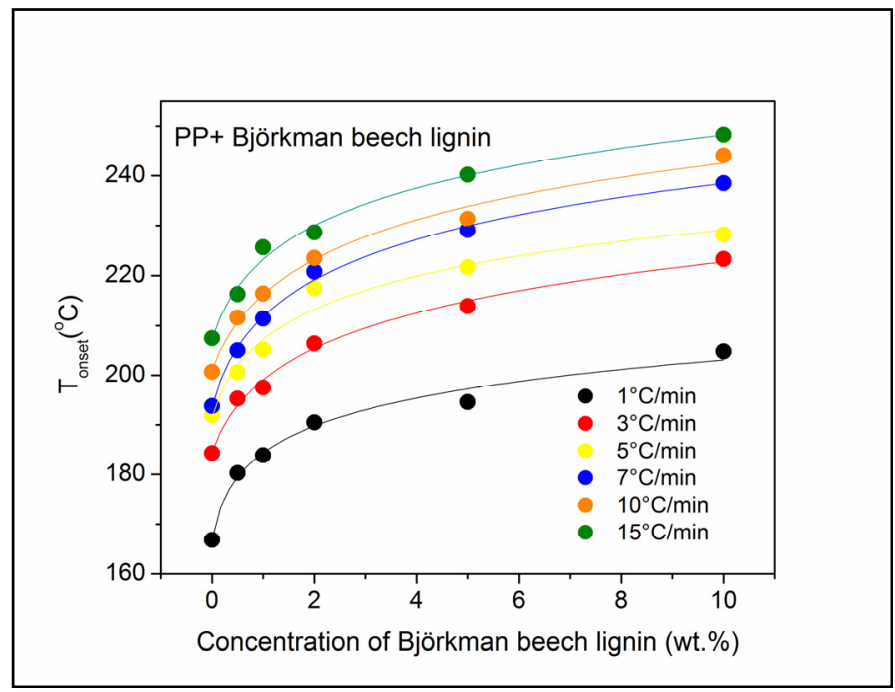

Figure 11. Thermal stability of polypropylene expressed as onset degradation temperature (Tonset) in dependence on lignin concentration, heating scan 30 to $500^{\circ} \mathrm{C}$, heating rate of $1,3,5,7,10$ and 15 ${ }^{\circ} \mathrm{C} / \mathrm{min}$, oxygen flow (Gregorova et al., 2005a).

\section{Thermal properties of poly(lactic acid) composites}

The incorporation of filler in PLA may change its crystallization behaviour and consequently its thermal properties. Some filler, such as wood flour or wood fibers, promote the transcrystallization and thus modify crystalline morphology of PLA (Mathew et al.; 2005 Pilla et al., 2008; Matthew et al., 2006; Hrabalova et al. 2010). This section describes the ability of hydrothermally pretreated beech flour to support a nucleation of PLA. Moreover, the effect of quick cooling and thermal annealing during thermal processing of PLA films is recorded. 
The sample used in this section were thermoplastic processed compounds of commercial poly(lactic acid) (PLA 7000D, NatureWorks LLC, USA) plasticized with $10 \mathrm{vol} \%$ of polyethylene glycol 1500 and filled with $30 \mathrm{wt} \%$ of hydrothermally pretreated beech flour (Gregorova et al., 2011b). Composite films were prepared by thermal molding in press at $160^{\circ} \mathrm{C}, 10 \mathrm{MPa}$ for $5 \mathrm{~min}$ and by modification of cooling process were prepared two morphologies: amorphous (quick cooling) and semi-crystalline (thermal annealing at $100^{\circ} \mathrm{C}$ for $\left.45 \mathrm{~min}\right)$. The samples are designated as pPLA_X_100_Y, where $\mathrm{X}$ indicates filler (0-no filler, WF- hydrothermally pretreated beech flour) and $\mathrm{Y}$ shows annealing time.

The thermal behavior of quenched and annealed PLA composites, investigated by differential scanning calorimetry (heating cycle from 20 to $180^{\circ} \mathrm{C}, 10^{\circ} \mathrm{C} / \mathrm{min}, 60 \mathrm{ml} / \mathrm{L}$ nitrogen flow) is summarized in Table 11 and shows that both filler incorporation of wood flour and thermal annealing influenced melting behavior and crystallinity of PLA composites. Specific melting enthalpy as an indicator of crystallinity degree of PLA in the composite was calculated as follows:

$$
\Sigma \Delta H=\frac{\left(\Delta H_{m 1}+\Delta H_{m 2}\right)-\Delta H_{c}}{v}
$$

where $\Delta \mathrm{H}_{\mathrm{m} 1}$ and $\Delta \mathrm{H}_{\mathrm{m} 2}$ are enthalpy values of the first and second melting peak, $\Delta \mathrm{H}_{\mathrm{c}}$ is the enthalpy of the cold crystallization and $v$ is volume fraction of PLA in the composite.

\begin{tabular}{|l|l|l|l|l|l|l|l|l|l|}
\hline \multicolumn{7}{|c|}{$1^{\text {st }}$ heating cycle } & $2^{\text {nd }}$ heating cycle \\
\hline Sample & $\begin{array}{l}\Delta \mathrm{H}_{\mathrm{c}} \\
(\mathrm{J} / \mathrm{g})\end{array}$ & $\begin{array}{l}\mathrm{T}_{\mathrm{c}} \\
\left({ }^{\circ}\right)\end{array}$ & $\begin{array}{l}\Delta \mathrm{H}_{\mathrm{m} 1} \\
(\mathrm{~J} / \mathrm{g})\end{array}$ & $\begin{array}{l}\mathrm{T}_{\mathrm{m} 1} \\
\left(^{\circ}\right)\end{array}$ & $\begin{array}{l}\Delta \mathrm{H}_{\mathrm{m} 2} 2 \\
(\mathrm{~J} / \mathrm{g})\end{array}$ & $\begin{array}{l}\mathrm{T}_{\mathrm{m} 2} \\
\left({ }^{\circ}\right)\end{array}$ & $\Sigma \Delta \mathrm{H}(\mathrm{J} / \mathrm{g})$ & $\Delta \mathrm{H}_{\mathrm{m} 1} / \Delta \mathrm{H}_{\mathrm{m} 2} 2$ & $\begin{array}{l}\mathrm{T}_{\mathrm{g}} \\
\left({ }^{\circ} \mathrm{C}\right)\end{array}$ \\
\hline pPLA_0_100_0 & 18.5 & 82 & 0.4 & 134 & 23.7 & 150 & 5.6 & 0.02 & 35 \\
pPLA_0_100_45 & - & - & 11.8 & 142 & 14.2 & 152 & 26.0 & 0.83 & 35 \\
pPLA_WF_100_0 & 14.2 & 95 & 1.7 & 140 & 12.9 & 151 & 0.4 & 0.13 & 43 \\
pPLA_WF_100_45 & - & - & 6.1 & 148 & 8.4 & 155 & 14.4 & 0.73 & 45 \\
\hline
\end{tabular}

Table 7. DSC thermal data of non-annealed and annealed PLA composites determined (Gregorova et al.; 2011b)

Samples that were after melting quickly cooled down to room temperature (quenched) exhibit cold crystallization and the double melting behavior that may be attributed to the melting of the original crystals and those of formed through the cold crystallization from the glassy state (Ling \& Spruiell, 2006). The known slow crystallization ability of PLA and quick cooling process caused that quenched samples remained mostly amorphous that was proved by low value of specific enthalpy $\Sigma \Delta H$. Thermograms of annealed samples displayed a marked double melting peak showing high degree of crystallinity (Gregorova et al.; 
2011b). The presence of filler marginally decreased specific enthalpy values of PLA. The presence of multiple melting peaks in thermograms of annealed samples can be explained by applied annealing that induce other crystal population, namely $\alpha^{\prime}$ (initially created with grain like morphology) and $\alpha$ (during annealing created with spherulitic morphology) crystals (Zhang et al., 2008; Pan et al., 2008). Melting temperature for unannealed neat or filled PLA samples were recorded between $134-140^{\circ} \mathrm{C}$ for the first melting peak and 150$151^{\circ} \mathrm{C}$ for the second melting peak. The growth of crystals during annealing increased the values of temperature of both melting peaks depending on the mixture composition. The change in the value of the ratio of the first and the second melting peaks indicates the modification of size of the present crystals. The $T g$ value after an annealing treatment can be taken as an indicator for the occurred changes in an amorphous/crystal ratio but also in PLA/filler interaction level. The increase of an interfacial compatibility between wood filler and poly(lactic acid) can be detected by an shift of a glass transition to the higher temperature (Gregorova \& Wimmer, 2012).

\section{Conclusions}

Differential scanning calorimetry is the method to characterize thermal behavior of polymeric materials on the base of the differences obtained in the heat flow between a sample and a reference under various temperature programs. In the addition to the quality and compositional analyses of polymers, DSC is applicable to the investigation of the thermal changes occurring in polymer systems during chemical reactions (e.g. polymerisation), oxidative degradation, vaporization, sublimation and desorptionThe selection of a proper temperature program is an important issue for the proper DSC analysis (e.g. a position and a shape of melting peak depend inherently on the nature of polymer and on the used heating scan rate). Thermal properties of biopolymers depend on many factors such as their natural origin, purity, composition, processing, thermal treatment, mechanical stressing, and aging. In this chapter, non-isothermal DSC was introduced as an method to investigate thermal properties of biopolymers, namely amorphous lignin and semi-crystalline poly(lactic acid). It can be concluded that DSC is one of the available methods to determine thermal properties of lignin with various molecular weight properties and composition.. Moreover, DSC can serve as a method to determine stabilizing effect of lignin used as an additive in polymer samples. Furthermore, DSC can be used as the quick method to measure melting behavior and the crystallinity of poly(lactic acid). The thermal history during polymer processing as well as the incorporation of some filler (e.g. wood flour) or additives can modify the crystallinity of PLA. The percentage of the crystallinity is one of the most important characteristics that influence its physico-mechanical behavior (stiffness, toughness, brittleness, barrier resistance, thermal stability and optical clarity). DSC is the valuable method for the investigation of thermal properties of biopolymers. However, it is necessary to use also the other additional physical and chemical testing methods to obtain complex data describing biopolymers, such as lignin and poly(lactic acid). 


\section{Author details}

Adriana Gregorova

Graz University of Technology, Institute for Chemistry and Technology of Materials, Austria

\section{References}

Bower, B.I. (2002). An Introduction to Polymer Physics. Cambridge University Press, New York

Di Lorenzo, M.L. (2006). The Crystallization and Melting Processes of Poly(L-lactic acid). Macromol. Symp., Vol.234, pp. 176-183

Gregorova, A.; Cibulkova, Z.; Kosikova, B.\& Simon P. (2005a). Stabilization effect of lignin in polypropylene and recycled polypropylene. Polymer Degradation and Stability, Vol. 89, No. 3, pp. 553-558, ISSN 0141-3910

Gregorova, A.; Kosikova, B.\& Osvald, A. (2005b). The study of lignin influence on properties of polypropylene composites. Wood Research, Vol. 50, No. 2, pp. 41-48, ISSN 1336-4561

Gregorova A.; Schalli M.\& Stelzer F. (2011a). Functionalization of polylactic acid through azeotropic dehydrative condensation. 19th Annual Meeting of the BioEnvironmental Polymer Society BEPS, Book of Abstracts, PO-4, ISBN 978-3-9502992-3-6, Vienna Austria, September 2011

Gregorova, A.; Sedlarik, V.; Pastorek, M.; Jachandra, H.\& Stelzer, F. (2011b). Effect of compatibilizing agent on the properties of highly crystalline composites based on poly(lactic acid) and wood flour and/or mica. Journal of Polymers and the Environment, Vol. 19, No.2, pp. 372-381, ISSN 1566-2543

Gregorova, A\& Wimmer R. (2012). Filler-Matrix Compatibility of Poly(lactic acid) Based Composites. In: Piemonte V., Editor. Polylactic Acid: Synthesis, Properties and Applications, Piemonte, V., pp. 97-119, Nova Science Publishers NY, ISBN 978-162100-348-9

Hatakeyama, H. \& Hatakeyama T. (2010). Lignin Structure, Properties and Applications. In: Biopolymers Lignin, Proteins, Bioactive Nanocomposites, Abe A., Dusek K., Kobayashi S., pp. 11-12, Springer-Verlag Berlin Heidelberg

Hrabalova, M.; Gregorova, A.; Wimmer, R.; Sedlarik, V.; Machovsky, M.\& Mundigler N. (2010). Effect of Wood Flour Loading and Thermal Annealing on Viscoelastic Properties of Poly(lactic acid) Composite Films. Journal of Applied Polymer Science, Vol. 118, No. 3, pp. 1534-1540, ISSN 1097-4628

Kopinke, F.D.; Remmler, M.; Mackenzie, K.; Möder, M.\& Wachsen, O. (1996). Thermal decomposition of biodegradable polyesters-II. Poly(lactic acid). Polymer Degradation and Stabilitity, Vol. 53, No. 3, pp. 329-342, ISSN 0141-3910 
Kosikova, B.; Kacurakova, M.\& Demianova V. (1993a). Photooxidation of the composite lignin/polypropylene films. Chemical Papers, Vol.47, pp. 132-136, ISSN 03666352

Kosikova, B.; Demianova, V.\& Kacurakova, M. (1993b). Sulphur-free lignins as composites of polypropylene films. Journal of Applied Polymer Science, Vol. 47, No. 6, pp. 1065-1073, ISSN 1097-4628

Kosikova, B.; Gregorova, A.; Osvald, A.\& Krajcovicova, J. (2007). Role of Lignin Filler in Stabilization of Natural Rubber-Based Composites. Journal of Applied Polymer Science, Vol. 103, No. 2, pp. 1226-1231, ISSN 1097-4628

Lee, S-H.; Kim, S.H.; Han, Y-K.\& Kim Y.H. (2001). Synthesis and degradation of end-groupfunctionalized polylactide. Journal of Polymer Science Part A: Polymer Chemistry, Vol. 39, No. 7, pp. 973-985, ISSN 1099-0518

Ling, X.\& Spruiell, J.E. (2006). Analysis of the complex thermal behaviour of poly(L-lactic acid) film. I. Samples crystallized from the glassy state. Journal of Polymer Science Part B: Polymer Physics, Vol. 44, No. 22, pp. 3200-3214, ISSN 1099-0488

Mathew, A.P.; Oksman, K.\& Sain, M. (2005). Mechanical properties of biodegradable composites from poly lactic acid (PLA) and microcrystalline cellulose (MCC). Journal of Applied Polymer Science, Vol.97, No. 5, pp. 2014-2015, ISSN 1097-4628

Mathew, A.P.; Oksman, K.\& Sain, M. (2006). The effect of morphology and chemical characteristics of cellulose reinforcements on the crystallinity of polylactic acid. Journal of Applied Polymer Science, Vol. 101, No. 1, pp. 300-310, ISSN 1097-4628

Mikulasova, M.\& Kosikova, B. (1999). Biodegradability of lignin-polypropylene composite films. Folia Microbiologica, Vol. 44, pp. 669-672, ISSN 0015-5632

Pan, P.; Zhu, B.; Kai, W.; Dong, T.\& Inoue, Y. (2008). Polymorphic Transition in Disordered Poly(L-lactide) Crystals Induced by Annealing at Elevated Temperatures. Macromolecules, Vol.41, No. 12, pp. 4296-4304, ISSN 1520-5835

Pilla, S.; Gong, S.; O’Neil, E.; Rowell, M.\& Krzysik, A.M. (2008). Polylactide-pine wood flour composites. Polymer Engineering Science, Vol.48, No. 3, pp. 578-587, ISSN 15482634

Ramkumar, D.H.S.\& Bhattacharya, M. (1998). Steady shear and dynamic properties of biodegradable polyesters. Polymer Engineering Science, Vol. 38, No. 9, pp. 1426-1435, ISSN 1548-2634

Yasuniwa, M.; Tsubakihara, S.; Sugimoto, Y.\& Nakafuku, C. (2004). Thermal analysis of the double-melting behavior of poly(L-Lactic acid). Journal of Polymer Science Part B: Polymer Physics, Vol.42, No. 1, pp. 25-32, ISSN 1099-0488

Yasuniwa, M.; Tsubakihara, S.; Iura, K.; Ono, Y.; Dan, Y.\& Takashashi K. (2006). Crystallization behavior of Poly(L-lactic acid). Polymer, Vol. 47, No. 21, pp. 7554-7563, ISSN 0032-3861 
Yasuniwa, M.; Iura, K.\& Dan Y. (2007). Melting behavior of poly(L-lactic acid): Effects of crystallization temperature and time. Polymer, Vol. 48, No. 18, pp. 5398-5407, ISSN $0032-$ 3861

Zhang, J.; Tashiro, K.; Tsuji, H.\& Domb, A.J. (2008). Disorder-to-Order Phase Transition and Multiple Melting Behavior of Poly(L-lactide) Investigated by Simultaneous Measurements of WAXD and DSC. Macromolecules, Vol.41, No. 4, pp. 1352-1357, ISSN $1520-5835$ 